\title{
Relationship Between Hemoglobin Levels and Quality of Life During Radiation Therapy Plus Concomitant or Sequential Chemotherapy in Patients With Cancer and Anemia Treated With Epoetin Alfa
}

\author{
Daniel Shasha, MD,* Pierre Cremieux, $\mathrm{PhD},{ }^{\dagger}$ and Louis Harrison, MD,* New York, \\ New York and Montreal, Canada
}

\section{Key Words}

Anemia, chemoradiation, epoetin alfa, hemoglobin, incremental analysis, quality of life

\begin{abstract}
This study in patients with cancer and anemia, who were receiving chemoradiation and were treated with epoetin alfa, examined the relationship between hemoglobin level and quality of life (QOL), change in hemoglobin and change in QOL, and incremental ( $1 \mathrm{~g} / \mathrm{dL})$ increase in hemoglobin and related incremental improvement in QOL. Data from a multicenter, open-label, prospective study of once-weekly epoetin alfa therapy in anemic cancer patients receiving chemoradiation were used to retrospectively evaluate the relationship between hemoglobin changes and QOL changes via correlation and longitudinal analyses. A sample selection correction method was used to ensure unbiased results. QOL (energy, activity, overall QOL) was measured using the Linear Analog Scale Assessment. An incremental analysis determined the greatest incremental increase in QOL associated with a $1 \mathrm{~g} / \mathrm{dL}$ increase in hemoglobin level. Of the 777 patients enrolled, 464 met chemotherapy
\end{abstract}

and radiotherapy eligibility criteria. Of these, 359 (77\%) underwent two QOL assessments and were eligible for analysis. A nonlinear and statistically significant positive correlation was found between hemoglobin levels and Linear Analog Scale Assessment QOL scores ( $r=0.32$ [energy], 0.33 [activity], and 0.29 [overall QOL]; $P<.0001)$. An incremental analysis used regression methods to characterize the changes in hemoglobin levels and QOL scores. Hemoglobin change was found to be a statistically significant determinant of QOL changes $(P<.05)$. The greatest incremental QOL gain associated with a $1-\mathrm{g} / \mathrm{dL}$ change in hemoglobin occurred around hemoglobin $12 \mathrm{~g} / \mathrm{dL}$ (range, $11-13 \mathrm{~g} / \mathrm{dL}$ ). A direct relationship exists between hemoglobin increases and corresponding QOL increases. Maximal incremental gain in QOL occurred when hemoglobin was approximately $12 \mathrm{~g} / \mathrm{dL}$ (range, 11-13 g/dL). (JNCCN 2004;2:509-517)

Anemia is a well-recognized complication of chemotherapy $^{1}$ and also a frequent complication of radiation therapy (RT). Approximately $40 \%$ to $60 \%$ of patients presenting for RT are already anemic (hemoglobin $[\mathrm{Hb}]<12 \mathrm{~g} / \mathrm{dL}$ ), ${ }^{2}$ and anemia may worsen or develop during treatment. ${ }^{3}$ Most patients with cancer and anemia, including those receiving $\mathrm{RT}$, experience fatigue, which is often accompanied by functional impairment and decreased quality of life (QOL). ${ }^{4-9}$ Additionally, evidence shows that low Hb levels are associated with tumor hypoxia; increased local failures; and lower survival rates in cervical cancer, ${ }^{10-17}$ lung cancer, ${ }^{18,19}$ squamous cell head and neck cancer, ${ }^{20,21}$ and other solid tumors. ${ }^{22,23}$ Although the mechanism of tumor resistance in states of hypoxia is not fully known, anoxic 
Shasha et al.

tumor cells are protected from cytotoxic therapy and are 2 to 3 times more resistant to RT than normally oxygenated cells. ${ }^{24,25}$

Several large studies have shown that $\mathrm{Hb}$ level increases are directly correlated with significant improvements in QOL (independent of tumor response) in anemic patients receiving chemotherapy and treated with recombinant human erythropoietin $(\mathrm{r}-\mathrm{HuEPO}$, epoetin alfa; PROCRIT; Ortho Biotech Products, L.P., Bridgewater, NJ). ${ }^{26-29}$ A previous incremental analysis based on data from two of the studies involving anemic patients receiving chemotherapy ${ }^{26,27}$ and epoetin alfa found that the greatest incremental gain in QOL occurred when $\mathrm{Hb}$ levels reached $12 \mathrm{~g} / \mathrm{dL}$ (range, 11-13 $\mathrm{g} / \mathrm{dL}) .^{30}$ These data support the maintenance of $\mathrm{Hb}$ levels at $12 \mathrm{~g} / \mathrm{dL}$ to maximize QOL in anemic patients with cancer, a premise that has been supported by data from several studies of epoetin alfa in patients with chronic renal failure ${ }^{31-34}$ that support a target $\mathrm{Hb}$ level of $12 \mathrm{~g} / \mathrm{dL}$ or higher. Moreover, biologic data show that the human body strives to maintain optimal $\mathrm{Hb}$ levels and logarithmically increases the production of endogenous erythropoietin when $\mathrm{Hb}$ levels drop below $12 \mathrm{~g} / \mathrm{dL}^{35}$

The use of epoetin alfa at the start of RT in patients with cancer and anemia has been shown to increase $\mathrm{Hb}$ levels and decrease transfusion requirements during RT. ${ }^{36-39}$ We recently reported that once-weekly epoetin alfa therapy in anemic patients with nonmyeloid malignancies receiving $\mathrm{RT}$ either concomitantly or sequentially with chemotherapy increased $\mathrm{Hb}$ levels, decreased transfusion requirements, and improved functional status and QOL. ${ }^{40}$ The use of chemoradiation is frequently associated with more frequent or severe toxicities, including hematologic toxicity, than either modality alone. Also, QOL is increasingly used to assess the relative impact of different chemotherapy and RT regimens in patients with cancer as a basis for evaluating treatment options.

The objectives of the current analyses were to evaluate the relationships between the following in patients with cancer and anemia treated with epoetin alfa who received RT concomitantly or sequentially with chemotherapy in our recent study: (1) absolute $\mathrm{Hb}$ levels and QOL; (2) changes in Hb levels and changes in QOL; and (3) incremental (1 g/dL) increase in $\mathrm{Hb}$ and related incremental improvement in QOL.

\section{Methods and Materials}

\section{Patients and Design of Original Study}

Data for these post-hoc retrospective analyses were obtained from a prospective, open-label, nonrandomized, multicenter, 16-week study that evaluated the safety, efficacy, and clinical outcomes of onceweekly epoetin alfa in the treatment of patients with cancer and anemia who were receiving RT with concomitant or sequential chemotherapy. ${ }^{40}$ Enrolled patients were from community-based practices or academic institutions within the United States, had histologically confirmed nonmyeloid malignancies, were 18 years of age or older, were anemic $(\mathrm{Hb} \leq 11$ $\mathrm{g} / \mathrm{dL}$ ), and had a life expectancy of 6 months or more. Patients with brain metastases; uncontrolled hypertension; hypersensitivity to animal products or human albumin; or anemia because of iron deficiency, B12 deficiency, folate deficiency, hemolysis, or gastrointestinal bleeding were excluded. Also excluded were candidates for bone marrow or stem cell transplantation, those receiving peripheral blood progenitor cell therapy, and patients who had received epoetin alfa therapy within 6 months of study enrollment. Patients had received a total RT dose of $4,000 \mathrm{cGy}$ or more within 8 weeks before baseline or were scheduled to receive a total RT dose of 4,000 cGy or more or a course of RT lasting 4 weeks or more during the study.

Patients were treated with 40,000 units of epoetin alfa subcutaneously once per week, with the dose increased to 60,000 subcutaneously once per week at week 5 if $\mathrm{Hb}$ increased $1 \mathrm{~g} / \mathrm{dL}$ or less after 4 weeks of therapy. If $\mathrm{Hb}$ rose to more than $13 \mathrm{~g} / \mathrm{dL}$ at any time during the study, epoetin alfa was discontinued until $\mathrm{Hb}$ returned to $12 \mathrm{~g} / \mathrm{dL}$ or less, at which time treatment was restarted at $75 \%$ of the original dose and titrated accordingly. The dose of epoetin alfa was decreased to $75 \%$ of the original dose if $\mathrm{Hb}$ increased more than $1.3 \mathrm{~g} / \mathrm{dL}$ during any 2 -week period. If RT or chemotherapy was discontinued during the study, the patient could continue to receive epoetin alfa; however, final $\mathrm{Hb}$ and QOL assessments were performed at this time. At the time of RT or chemotherapy discontinuation, final $\mathrm{Hb}$ evaluations were performed. Iron-deficient patients received supplemental iron as clinically indicated by iron status evaluations (eg, transferrin saturation, serum ferritin levels). The formulation of iron administered was determined by patient and physician preference. 
Primary efficacy endpoints were hematologic parameters including $\mathrm{Hb}$ (measured at weeks 2, 4, 8, 12 , and 16), number of transfusions and units transfused (measured at week 4 and every 4 weeks thereafter). QOL, a secondary endpoint, was measured using self-reported Linear Analog Scale Assessment (LASA) scores for energy (energy), ability to perform daily activities (activity), and overall well-being (overall QOL). Patient-reported functional capacity and LASA measurements were performed at baseline, week 8 , and week 16 (or at early study discontinuation). At the time of RT or chemotherapy discontinuation, final LASA evaluations were performed.

\section{Statistical Analyses}

The population used in this analysis comprised all patients who had undergone at least two QOL assessments and received chemotherapy either concomitantly or sequentially with RT of at least 4,000 cGy or RT for a duration of at least 4 weeks during the study, regardless of change in $\mathrm{Hb}$ or QOL. Longitudinal data providing information on a given patient at the beginning and end of the study were used to determine changes in $\mathrm{Hb}$ and QOL. Cross-sectional correlation analyses were used to evaluate the strength of the relationship between $\mathrm{Hb}$ and LASA scores. Longitudinal patient-specific analyses were used to examine the relationship between changes in $\mathrm{Hb}$ levels and change in QOL scores. Patients' baseline and final QOL scores were paired with their closest $\mathrm{Hb}$ levels and other clinical measures. An incremental analysis was performed to examine the relationship between successive (incremental) 1 -g/dL Hb level increases and the corresponding change in QOL for a given patient. By examining the shape of the curve showing the relationship between $\mathrm{Hb}$ and QOL during epoetin alfa therapy, the target $\mathrm{Hb}$ range where the greatest gain in QOL might be obtained in response to a unit $\mathrm{Hb}$ change was determined.

A two-stage Heckman analysis, ${ }^{41}$ commonly used to address problems of missing data and sample selection bias, was performed to correct for potential bias resulting from patients who were clinically evaluated at least twice but failed or declined to complete a second QOL evaluation. This procedure identifies systematic characteristics of patients whose second QOL measurement is missing and includes a variable that embodies these characteristics into the analysis of patients with complete data, thereby reducing the likelihood of bias resulting from nonrandomly missing data. Control variables in the Heckman analysis included age, gender, ethnicity, tumor type, transfusion status, number of units transfused, presence of RT, presence of chemotherapy and regimen, and baseline QOL. Control variables also included whether $\mathrm{Hb}$ changed from baseline to final measurement. Despite its wide use and proven effectiveness at minimizing sample selection bias, the Heckman procedure has limitations, including the assumption that the variable embodying the characteristics of missing data has a linear additive effect on the outcome variable and the effectiveness of the instruments at characterizing the missing pattern in the first stage of the procedure. As a result, Heckman diagnostics and comparative statistics on the two groups (one and two or more QOL assessments) are provided.

All statistical analyses were performed using the SAS software (Cary, NC) or an equivalent software package. For graphic presentation of all statistical analyses, an $\mathrm{Hb}$ level of $8 \mathrm{~g} / \mathrm{dL}$ refers to levels from 7.5 to $8.49 \mathrm{~g} / \mathrm{dL} ; 9 \mathrm{~g} / \mathrm{dL}$ refers to levels from 8.5 to 9.49 $\mathrm{g} / \mathrm{dL}$; and so forth.

\section{Results}

\section{Patient Characteristics and Sample Selection Correction}

Of the initial 777 patients enrolled, 464 met the criteria of chemotherapy and RT treatment (RT 4,000 cGy or more or RT duration of at least 4 weeks). Of these, 442 (95\%) underwent at least two Hb assessments and were evaluable for hematologic response, and $359(77 \%)$ were evaluable for QOL assessments (i.e., completed two or more QOL assessments). Twenty-six patients were excluded because they did not meet eligibility requirements, five were removed because of unclear RT data, 282 did not meet the RT dose requirement or were scheduled for RT but did not receive it, and 22 did not receive chemotherapy. Eighty-three patients were not evaluable for QOL response: 82 patients did not have two QOL assessments and one patient was missing a baseline QOL assessment. An additional 151 patients withdrew before study completion.

Baseline demographic data are presented in Table 1 for the 442 patients with at least two $\mathrm{Hb}$ assessments and the subset of patients with one and with two or more QOL assessments. Population characteristics 
Shasha et al.

\begin{tabular}{|c|c|c|c|}
\hline Characteristic & $\begin{array}{l}\text { Full } \\
\text { Sample } \\
(N=464)\end{array}$ & $\begin{array}{l}\geq 2 \text { QOL } \\
\text { Assessments } \\
(n=359)\end{array}$ & $\begin{array}{l}<2 \text { QOL } \\
\text { Assessments } \\
(n=105)\end{array}$ \\
\hline \multicolumn{4}{|l|}{$\operatorname{Sex}(\%)^{a}$} \\
\hline Male & 42.8 & 40.1 & 45.8 \\
\hline Female & 57.2 & 59.9 & 54.2 \\
\hline Mean age (years) & 61.7 & $61.2 \pm 12.6$ & $63.8 \pm 12.2$ \\
\hline Mean $( \pm \mathrm{SD}) \mathrm{Hb}(\mathrm{g} / \mathrm{dL})(n=442)^{\mathrm{a}}$ & $9.9 \pm 0.8$ & $10.0 \pm 0.8$ & $9.7 \pm 0.9$ \\
\hline \multicolumn{4}{|l|}{ Mean $\left( \pm\right.$ SD) LASA $(m m)^{\mathrm{b}}(n=359)^{\mathrm{a}}$} \\
\hline Energy level & $42.5 \pm 22.1$ & $42.5 \pm 22.1$ & $36.2 \pm 21.8$ \\
\hline Activity level & $42.8 \pm 25.1$ & $42.8 \pm 25.1$ & $37.6 \pm 27.0$ \\
\hline Overall QOL level & $48.1 \pm 25.2$ & $48.1 \pm 25.2$ & $43.2 \pm 26.9$ \\
\hline \multicolumn{4}{|l|}{ ECOG performance status $(n=441)^{\mathrm{a}}$} \\
\hline 0 & $25 \%$ & $26 \%$ & $17 \%$ \\
\hline 1 & $49 \%$ & $49 \%$ & $49 \%$ \\
\hline 2 & $20 \%$ & $20 \%$ & $20 \%$ \\
\hline 3 & $6 \%$ & $15 \%$ & $4 \%$ \\
\hline 4 & $<1 \%$ & $<1 \%$ & $<1 \%$ \\
\hline Transfusion rate ${ }^{c}$ & $10.2 \%$ & $9.5 \%$ & $13.2 \%$ \\
\hline
\end{tabular}

Abbreviations: Hb, hemoglobin; LASA, Linear Analog Scale Assessment; QOL, quality of life; ECOG, Eastern Cooperative Oncology Group.

andicates a statistically significant $(P<.05)$ difference between patients with 1 vs. $\geq 2$ QOL assessments.

${ }^{b}$ Expressed on a 100-mm scale, with 0 representing lowest self-perception of each parameter and 100 representing highest self-perception.

'Baseline transfusion rate represents the proportion of patients requiring transfusions within the 6-month period prior to epoetin alfa initiation.

stratified by number of QOL assessments showed statistically significant $(P<.05)$ differences in gender distribution, baseline $\mathrm{Hb}$ level, and LASA energy score, as well as Eastern Cooperative Oncology Group (ECOG) performance status. Diagnostics on the Heckman sample selection correction indicated that the approach effectively predicted the probability of having two QOL assessments $\left(\chi^{2}=35.8 ; 36.3\right.$; and 36.3 for LASA energy, activity, and overall QOL, respectively; $P<.01)$ and that the correction variable included in the second stage (the hazard of having at least two QOL readings) was jointly significant in all three analyses $(P<.01)$. These results indicate that the sample population of patients with at least two QOL assessments $(n=359)$ showed differences compared with the population of patients with fewer than two QOL assessments $(n=105)$, but that the Heckman sample selection correction alleviated any bias that could have resulted from these differences.
Overall, the baseline $\mathrm{Hb}$ level of evaluable patients was $9.9 \pm 0.8 \mathrm{~g} / \mathrm{dL}$, and $10.2 \%$ of patients had received transfusions within 6 months of epoetin alfa initiation. Most patients (97.6\%) had nonhematologic malignancies, with the lungs being the most common disease site (41.6\% of patients). A variety of chemotherapeutic agents were administered concurrently or sequentially with epoetin alfa, with carboplatin and paclitaxel the most common. The mean total RT dose received (before and during epoetin alfa therapy) was 5,502 cGy. Mean baseline LASA scores ( \pm standard deviation [SD]) for the 359 evaluable patients for energy, activity, and overall QOL were all below $50 \mathrm{~mm}(42.5 \pm 22.1 \mathrm{~mm}$, $42.8 \pm 25.1 \mathrm{~mm}$, and $48.1 \pm 25.2 \mathrm{~mm}$, respectively), suggesting significant patient-perceived functional impairment. In a healthy population (without cancer or serious comorbidities), expected mean LASA scores are $85 \mathrm{~mm}$ or higher for individuals 21 to 50 
years of age and 70 to $80 \mathrm{~mm}$ for those 51 years or older. ${ }^{42}$

\section{Relationship Between Absolute Hb Levels and QOL}

The mean increase in $\mathrm{Hb}$ level from baseline to final measurement was $1.9 \pm 1.8 \mathrm{~g} / \mathrm{dL}(P<.05)$. Based on data obtained at baseline, week 8 , and week 16 or early withdrawal, direct correlations between $\mathrm{Hb}$ levels and LASA scores for energy, activity, and overall QOL were statistically significant $(r=0.32,0.33$, and 0.29 , respectively; $P<.0001$ for each; Fig. 1$)$. The relationship between $\mathrm{Hb}$ and $\mathrm{QOL}$ was nonlinear and is perhaps one possible explanation for the modest correlation coefficients, which measure the degree of linear correlation between two variables. Alternatively, other factors besides $\mathrm{Hb}$ may have effects on QOL, which suggests the need for a multivariate regression analysis presented in the following section.

\section{Relationship Between Changes in Hb Levels and Changes in QOL Scores}

A positive relationship between patients' $\mathrm{Hb}$ levels and QOL scores implies that patients with higher

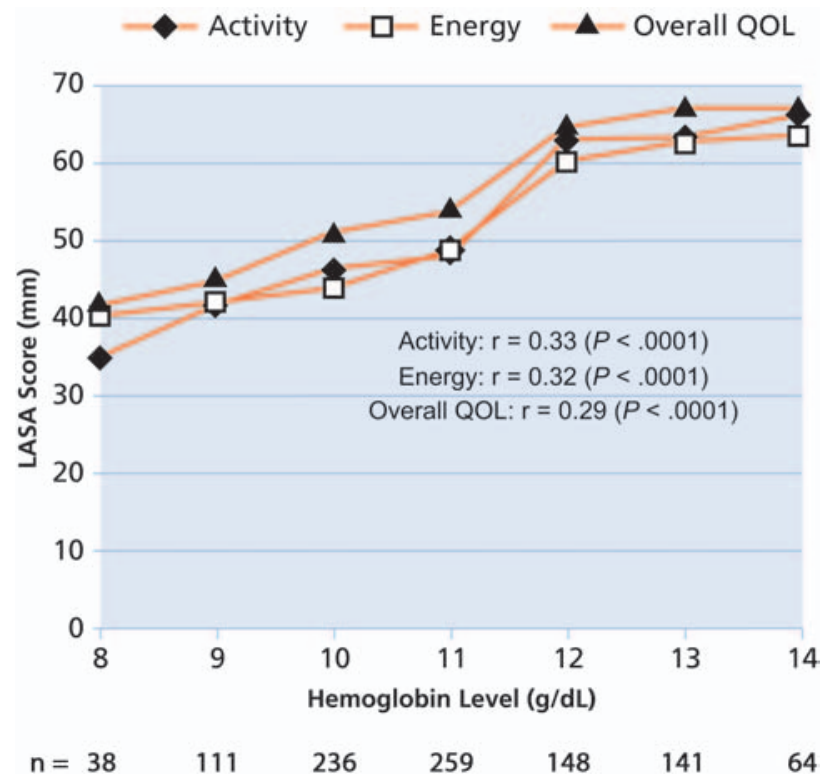

Figure 1 Hemoglobin ( $\mathrm{Hb}$ ) levels and associated Linear Analog Scale Assessment (LASA) scores for activity, energy, and overall quality of life (QOL). Data collected at baseline, week 8, and week 16 or early withdrawal were included in the analyses. The last $\mathrm{Hb}$ category is omitted in the figure because there were too few observations $(<20)$. $\mathrm{Hb}$ levels represented on the $\mathrm{x}$-axis represent the midpoint of the range (i.e., $8 \mathrm{~g} / \mathrm{dL}$ refers to levels between 7.49 and $8.5 \mathrm{~g} / \mathrm{dL} ; 9 \mathrm{~g} / \mathrm{dL}$ refers to levels between 8.5 and $9.49 \mathrm{~g} / \mathrm{dL}$; and so forth).
$\mathrm{Hb}$ levels will also experience improved QOL. Determining this relationship, however, requires that the relationship between $\mathrm{Hb}$ and QOL be observed for each individual patient across time rather than across individual patients at each point in time. A change on the $100-\mathrm{mm}$ LASA scale of approximately $10 \mathrm{~mm}$ has been shown to represent a minimally important difference (MID) for changes in health-related QOL scores in patients with anemia and cancer, and signifies the smallest difference in LASA overall QOL score that has a clinically meaningful effect on patients' self-perceived QOL. ${ }^{43}$

A regression analysis of the relationship between changes in $\mathrm{Hb}$ levels and changes in LASA scores for energy, activity, and overall QOL, together with a Heckman procedure correcting for the potential selfselection bias arising from the nonrandom dropout of patients, showed that increases in $\mathrm{Hb}$ yielded longitudinal improvements in LASA scores. Figure 2 displays this relationship between $\mathrm{Hb}$ and LASA overall QOL. A similar relationship was apparent for LASA energy levels and activity levels. Four covariates were used to adjust for their possible

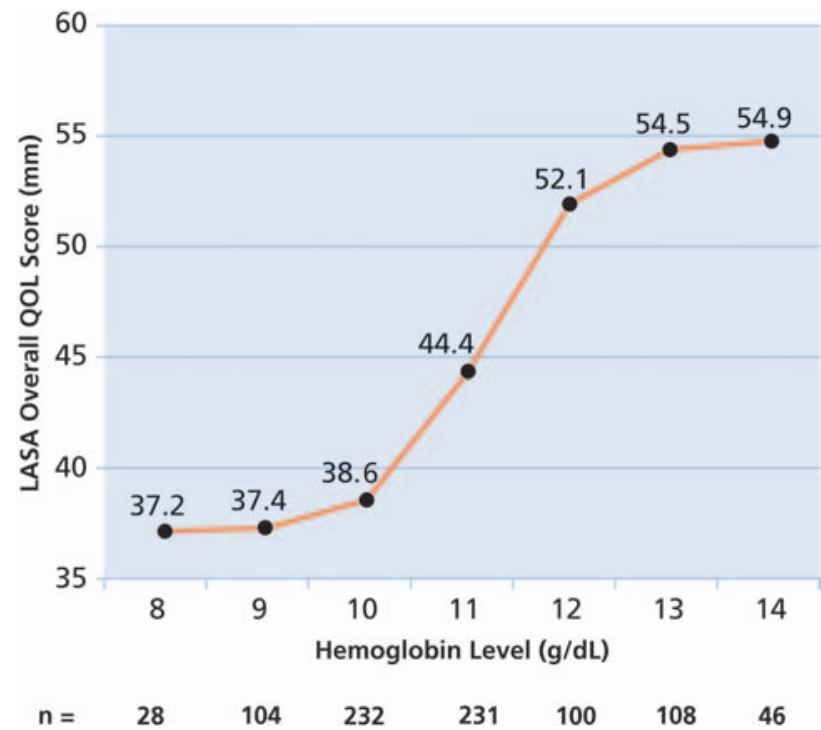

Figure 2 Longitudinal analysis of the relationship between changes in hemoglobin $(\mathrm{Hb})$ levels and changes in Linear Analog Scale Assessment (LASA) scores for overall quality of life (QOL) during epoetin alfa therapy. $\mathrm{Hb}$ levels recorded on the $\mathrm{x}$-axis represent the midpoint of the $\mathrm{Hb}$ range (i.e., $8 \mathrm{~g} / \mathrm{dL}$ refers to levels between 7.49 and $8.5 \mathrm{~g} / \mathrm{dL} ; 9 \mathrm{~g} / \mathrm{dL}$ refers to levels between 8.5 and $9.49 \mathrm{~g} / \mathrm{dL}$; and so forth). Data collected at baseline, week 8 , and week 16 were included in the analyses. The last $\mathrm{Hb}$ category $(>14.5)$ is omitted from the figure because there were too few observations $(<20)$. Hb change variables were jointly significant in predicting QOL changes for all three QOL measures $(P<.05)$. 
Shasha et al.

confounding effects on the relationship between change in $\mathrm{Hb}$ and change in LASA score: change in transfusion status, change in number of units transfused, change in chemotherapy, and change in radiotherapy. At an $\mathrm{Hb}$ level of $14 \mathrm{~g} / \mathrm{dL}$, the estimated scores for activity, energy, and overall QOL were, respectively, 17.0, 16.3, and $17.7 \mathrm{~mm}$ higher than at an $\mathrm{Hb}$ level between $7.5 \mathrm{~g} / \mathrm{dL}$ and $8.49 \mathrm{~g} / \mathrm{dL}$ (Hb coefficients were jointly significant at $P<.001$ for all three categories). In addition, the mean increase in LASA overall QOL score when $\mathrm{Hb}$ increased from $10 \mathrm{~g} / \mathrm{dL}$ to $12 \mathrm{~g} / \mathrm{dL}$ was $13.5 \mathrm{~mm}$.

\section{Relationship Between Incremental Increases in $\mathrm{Hb}$ Levels and QOL Scores}

The changing slopes in the sigmoid-shape curve imply that incremental increases in $\mathrm{Hb}$ have different effects on patients' QOL response, depending on $\mathrm{Hb}$ level. Figure 3 illustrates the effect of an incremental $(1 \mathrm{~g} / \mathrm{dL})$ increase in $\mathrm{Hb}$ level on LASA overall QOL scores based on the average 2 -g/dL increase seen among

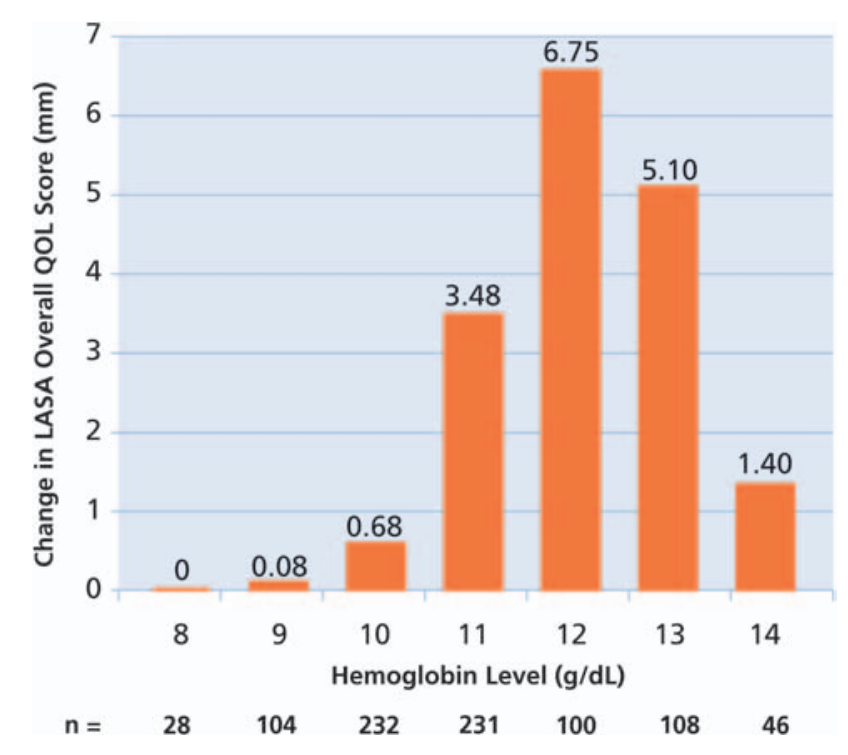

Figure 3 Incremental analysis of the relationship between changes in hemoglobin ( $\mathrm{Hb})$ levels and changes in Linear Analog Scale Assessment (LASA) scores for overall quality of life (QOL) during epoetin alfa therapy. Hb levels recorded on the $\mathrm{x}$-axis represent the midpoint of the $\mathrm{Hb}$ range (i.e., $8 \mathrm{~g} / \mathrm{dL}$ refers to levels between $7.5 \mathrm{~g} / \mathrm{dL}$ and $8.49 \mathrm{~g} / \mathrm{dL} ; 9 \mathrm{~g} / \mathrm{dL}$ refers to levels between 8.5 and $9.49 \mathrm{~g} / \mathrm{dL}$; and so forth) reached after a $2-\mathrm{g} / \mathrm{dL}$ increase. The figure represents the average effect of a $1-\mathrm{g} / \mathrm{dL}$ increase for such a patient. Data collected at baseline, week 8 , and week 16 were included in the analyses. The last Hb category $(>14.5 \mathrm{~g} / \mathrm{dL})$ is omitted from the figure because there were too few observations $(<20)$. Hb change variables were jointly significant in predicting QOL changes for all three QOL measures $(P<.05)$. evaluable patients in the trial. The greatest incremental gain in QOL, as measured by change in LASA score per unit change in $\mathrm{Hb}$ level, occurred when reaching an $\mathrm{Hb}$ of $12 \mathrm{~g} / \mathrm{dL}$. Beyond an $\mathrm{Hb}$ of $12 \mathrm{~g} / \mathrm{dL}$, additional gains in QOL continued to be seen, but were of a reduced magnitude. Because this finding is based on a longitudinal analysis of the data, it reflects the QOL response to an $\mathrm{Hb}$ level change in a given patient rather than differences in QOL reported by different patients.

\section{Discussion}

In the management of patients with cancer, QOL influences patients' attitudes towards treatment, ability to cope, and overall well-being. Consequently, greater emphasis is being placed on the patient's perception of QOL for decisions related to therapeutic options. Patients who receive chemoradiation are likely to experience new onset or exacerbated anemia as a consequence of therapy. In addition to contributing to fatigue and worsened QOL, anemia is also associated with decreased local tumor response rates and overall survival during RT. Thus, more aggressive treatment of anemia in the radiation oncology setting offers the potential to improve QOL and possibly treatment outcomes. ${ }^{44} \mathrm{We}$ recently reported the results of a prospective, multicenter, open-label study of once-weekly epoetin alfa in anemic patients receiving chemoradiation. ${ }^{40}$ As in patients with cancer and anemia receiving chemotherapy, ${ }^{26-29}$ epoetin alfa therapy increased $\mathrm{Hb}$ levels, decreased transfusion requirements, and increased QOL scores.

Recent analyses reported by Crawford et al..$^{30}$ based on data from studies of epoetin alfa for the treatment of anemia in patients receiving chemotherapy provided new insights into the relationship between anemia and QOL. Because these types of QOL data are difficult to find and important to replicate to support their validity and reproducibility, we sought to perform similar analyses, but expanded to a population of anemic patients receiving chemoradiation. As with the analyses in patients with cancer and anemia receiving chemotherapy, the cross-sectional correlation analyses in our study also showed statistically significant and direct positive correlations between $\mathrm{Hb}$ levels and QOL scores, as measured by LASA in both settings. 
A longitudinal approach using patients as their own controls indicated that patients experienced improvements in QOL in response to increasing $\mathrm{Hb}$ levels after adjusting for confounding factors that affect QOL outcomes over time, such as baseline QOL, transfusion requirements, and type of chemotherapy or RT received. As in the incremental analysis by Crawford et $a{ }^{30}$ in anemic patients with cancer receiving chemotherapy and epoetin alfa, all three LASA QOL parameters improved with increasing $\mathrm{Hb}$ levels until an $\mathrm{Hb}$ level of $14 \mathrm{~g} / \mathrm{dL}$ was obtained, with the greatest QOL gains made with successive increases in $\mathrm{Hb}$ up to a level of $12 \mathrm{~g} / \mathrm{dL}$. At Hb levels thereafter (12 $\mathrm{g} / \mathrm{dL}$ to $14 \mathrm{~g} / \mathrm{dL}$ ), gains in QOL continued to be seen, although they were of a lesser magnitude. Also, as with the analyses in patients with cancer and anemia receiving chemotherapy, ${ }^{30}$ our incremental analysis showed that increasing $\mathrm{Hb}$ levels during epoetin alfa therapy were associated with corresponding increases in QOL scores. In our study of epoetin alfa in patients with cancer and anemia receiving RT concomitantly or sequentially with chemotherapy, the maximum QOL change for an incremental increase in $\mathrm{Hb}$ level occurred at and around $12 \mathrm{~g} / \mathrm{dL}$, as it did in the incremental analysis in patients with cancer and anemia receiving chemotherapy and epoetin alfa. ${ }^{30}$

The statistical analysis conducted on patients with two QOL measurements paired with the sample bias correction used to address the nonrandom dropout of sicker patients yielded results applicable to all patients receiving concomitant or sequential chemotherapy and radiotherapy; however, it excludes patients receiving chemotherapy or radiotherapy alone. As mentioned previously, similar results have been reported in other research, which includes patients receiving chemotherapy only. ${ }^{30}$

The findings of our analyses are clinically relevant and complement the growing body of evidence showing a direct relationship between incremental $\mathrm{Hb}$ level increases and corresponding QOL improvements in patients with cancer and anemia receiving chemotherapy and/or RT. Collectively, results from the analyses reported here and those of Crawford et al. ${ }^{30}$ indicate that a change in the therapeutic management of cancer treatment-related anemia should be considered.

Traditionally, chemotherapy-related and RT-related anemia has been treated with epoetin alfa or transfusions when $\mathrm{Hb}$ levels fall to $10 \mathrm{~g} / \mathrm{dL}$ or below, and current evidence-based clinical practice guidelines for cancer patients with anemia issued by the American Society of Hematology (ASH) and the American Society of Clinical Oncology (ASCO) currently recommend epoetin alfa as a treatment option when $\mathrm{Hb}$ levels drop to $10 \mathrm{~g} / \mathrm{dL}$ or less. However, our results show that increasing $\mathrm{Hb}$ from $10 \mathrm{~g} / \mathrm{dL}$ to 12 $\mathrm{g} / \mathrm{dL}$ produces a clinically meaningful ${ }^{43}$ improvement in QOL (as shown by a mean increase in LASA overall QOL score of $13.5 \mathrm{~mm}$ ), indicating that $\mathrm{Hb}$ levels less than $12 \mathrm{~g} / \mathrm{dL}$ are associated with impaired functional ability. Given that up to $72 \%$ of patients with cancer have $\mathrm{Hb}$ less than $12 \mathrm{~g} / \mathrm{dL},{ }^{45}$ these findings support early intervention with epoetin alfa in anemic patients to maximize QOL and to prevent more severe anemia from developing. Early anemia intervention with epoetin alfa may be especially important for patients receiving RT, because studies have suggested that $\mathrm{Hb}$ levels greater than $11 \mathrm{~g} / \mathrm{dL}$ may be associated with better tumor response rates and overall survival during RT. ${ }^{10-12,16-20}$ However, in light of recent studies showing impaired survival relative to placebo in nonanemic patients with metastatic breast cancer ${ }^{46}$ receiving epoetin alfa and chemotherapy or patients with head and neck cancer ${ }^{47}$ receiving epoetin beta and radiotherapy, the goal of epoetin alfa treatment should be to achieve a target $\mathrm{Hb}$ of $12 \mathrm{~g} / \mathrm{dL}$. This recommendation to maintain an optimal $\mathrm{Hb}$ level of $12 \mathrm{~g} / \mathrm{dL}$ with erythropoietic therapy is also supported by the National Comprehensive Cancer Network (NCCN) guidelines for cancer- and treatment-related anemia. ${ }^{48}$

Our analyses provide additional evidence for a relationship between $\mathrm{Hb}$ level increases and corresponding improvements in QOL in patients with cancer and anemia receiving RT plus concomitant or sequential chemotherapy. Significant QOL improvements were seen with successive $\mathrm{Hb}$ level increases across the clinically relevant $\mathrm{Hb}$ range of $7.5 \mathrm{~g} / \mathrm{dL}$ to $14.5 \mathrm{~g} / \mathrm{dL}$. Importantly, in both our incremental study and the study of Crawford et al., ${ }^{30}$ the greatest incremental gain in QOL occurred when $\mathrm{Hb}$ reached 12 $\mathrm{g} / \mathrm{dL}$. Consequently, to improve patient well-being and optimize treatment outcomes in patients with cancer and anemia receiving chemotherapy with or without RT, clinicians should consider treating patients with even mild anemia (i.e., patients with $\mathrm{Hb}$ levels of $10 \mathrm{~g} / \mathrm{dL}$ to $12 \mathrm{~g} / \mathrm{dL}$ ), with consideration of $12 \mathrm{~g} / \mathrm{dL}$ as the optimal target for hemoglobin maintenance. ${ }^{48}$ 
Shasha et al.

\section{References}

1. Groopman JE, Itri LM. Chemotherapy-induced anemia in adults: Incidence and Treatment. J Natl Cancer Inst 1999;91: 1616-1634.

2. Harrison LB, Shasha D, Homel P. Prevalence of anemia in cancer patients undergoing radiotherapy: prognostic significance and treatment. Oncology 2002;63(suppl 2):11-18.

3. Harrison L, Shasha D, Shiaova L, et al. Prevalence of anemia in cancer patients undergoing radiation therapy. Semin Oncol 2001;28(suppl 8):54-59.

4. Irvine D, Vincent L, Graydon JE, et al. The prevalence and correlates of fatigue in patients receiving treatment with chemotherapy and radiotherapy: A comparison with the fatigue experienced by healthy individuals. Cancer Nurs 1994;17:367-378.

5. Vogelzang NJ, Breitbart W, Cella D, et al. Patient, caregiver, and oncologist perceptions of cancer-related fatigue: Results of a tripart assessment survey. Semin Hematol 1997;3(suppl 2):4-12.

6. Curt G, Breitbart W, Cella D, et al. Impact of cancer-related fatigue on the lives of patients: New findings from The Fatigue Coalition. Oncologist 2000;5:353-360.

7. Stone P, Richards M, A'Hern R, et al. Fatigue in patients with cancers of the breast or prostate undergoing radical radiotherapy. J Pain Symptom Manage 2001;22:1007-1015.

8. Wang XS, Janjan NA, Guo H, et al. Fatigue during preoperative chemoradiation for resectable rectal cancer. Cancer 2001;92(suppl 6):1725-1732.

9. Sobrero A, Puglisi F, Guglielmi A, et al. Fatigue: A main component of anemia symptomatology. Semin Oncol 2001;28(suppl 8):15-18.

10. Vigario G, Kurohara SS, George FW III. Association of hemoglobin levels before and during radiotherapy with prognosis in uterine cervix cancer. Radiology 1973;106:649-652.

11. Schreiner $P$, Siracká E, Siracký J, et al. The effect of anemia on the radiotherapy results of the uterine cervix cancer. Neoplasma 1975;22:655-660.

12. Bush RS, Jenkin RDT, Allt WEC, et al. Definitive evidence for hypoxic cells influencing cure in cancer therapy. Br J Cancer 1978;37(suppl III):302-306.

13. Girinski T, Pejovic-Lenfant MH, Bourhis J, et al. Prognostic value of hemoglobin concentrations and blood transfusions in advanced carcinoma of the cervix treated by radiation therapy: Results of a retrospective study of 386 patients. Int J Radiat Oncol Biol Phys 1989;16:37-42.

14. Fyles A, Milosevic M, Wong R, et al. Oxygenation predicts radiation response and survival in patients with cervix cancer. Radiother Oncol 1998;48:149-156.

15. Grogan M, Thomas GM, Melamed I, et al. The importance of hemoglobin levels during radiotherapy for carcinoma of the cervix. Cancer 1999;86:1528-1536.

16. Thomas $G$. The effect of hemoglobin level on radiotherapy outcomes: The Canadian experience. Semin Oncol 2001;28(suppl 8):60-65.

17. Obermair A, Cheuk R, Horwood K, et al. Impact of hemoglobin levels before and during concurrent chemoradiother- apy on the response of treatment in patients with cervical carcinoma: Preliminary results. Cancer 2001;92:903-908.

18. Dische S, Saunders MI, Warburton MF. Hemoglobin, radiation, morbidity and survival. Int J Radiat Oncol Biol Phys 1986;12:1335-1337.

19. Takigawa N, Segawa $Y$, Okahara M, et al. Prognostic factors for patients with advanced non-small cell lung cancer: Univariate and multivariate analyses including recursive partitioning and amalgamation. Lung Cancer 1996;15:67-77.

20. Fein DA, Lee WR, Hanlon AL, et al. Pretreatment hemoglobin level influenced local control and survival of T1-T2 squamous cell carcinomas of the glottic larynx. J Clin Oncol 1995;13:2077-2083.

21. Glaser CM, Millesi W, Kornek GV, et al. Impact of hemoglobin level and use of recombinant erythropoietin on efficacy of preoperative chemoradiation therapy for squamous cell carcinoma of the oral cavity and oropharynx. Int J Radiat Oncol Biol Phys 2001;50:705-715.

22. Constantinou E, Daly W, Fung C, et al. Time-dose considerations in the treatment of anal cancer. Int J Radiat Oncol Biol Phys 1997;39:651-657.

23. Dunphy EP, Petersen IA, Cox RS, et al. The influence of initial hemoglobin and blood pressure levels on results of radiation therapy for carcinoma of the prostate. Int J Radiat Oncol Biol Phys 1989;16:1173-1184.

24. Teicher BA. Physiologic mechanisms of therapeutic resistance: Blood flow and hypoxia. Hematol Oncol Clin North Am 1995;9:475-506.

25. Harrison LB, Chadha M, Hill RJ, et al. Impact of tumor hypoxia and anemia on radiation therapy outcomes. Oncologist 2002; 7:492-508.

26. Demetri G, Kris M, Wade J, et al, for the Procrit Study Group. Quality-of-life benefit in chemotherapy patients treated with epoetin alfa is independent of disease response or tumor type: Results from a prospective community oncology study. J Clin Oncol 1998;16:3412-3425.

27. Glaspy J, Bukowski R, Steinberg D, et al, for the Procrit Study Group. Impact of therapy with epoetin alfa on clinical outcomes in patients with nonmyeloid malignancies during cancer therapy in community oncology practice. J Clin Oncol 1997;15:1218-1234.

28. Littlewood TJ, Bajetta E, Nortier JWR, et al, for the Epoetin Alfa Study Group. Effects of epoetin alfa on hematologic parameters and quality of life in cancer patients receiving nonplatinum chemotherapy: Results of a randomized, double-blind, placebo-controlled trial. J Clin Oncol 2001;19: 2865-2874.

29. Gabrilove J, Cleeland C, Livingston R, et al. Clinical evaluation of once-weekly dosing of epoetin alfa in chemotherapy patients: Improvements in hemoglobin and quality of life are similar to three-times-weekly dosing. J Clin Oncol 2001;19:2875-2882.

30. Crawford J, Cella D, Cleeland CS, et al. Relationship between changes in hemoglobin level and quality of life during chemotherapy in anemic cancer patients receiving epoetin alfa therapy. Cancer 2002;95:888-895. 
31. Churchill DN, Muirhead N, Goldstein M, et al. Effect of recombinant human erythropoietin on hospitalization of hemodialysis patients. Clin Nephrol 1995;43:184-188.

32. Eschbach JW. The future of $r$-HuEPO. Nephrol Dial Transplant 1995;10(suppl 2):96-109.

33. Iseki $K$, Nishime $K$, Uehara $H$, et al. Increased risk of cardiovascular disease with erythropoietin in chronic dialysis patients. Nephron 1996;72:30-36.

34. Nissenson AR, Pickett JL, Theberge DC, et al. Brain function is better in hemodialysis patients when hematocrit is normalized with erythropoietin (Abstr). J Am Soc Nephrol 1996;7:1459.

35. Hillman RS, Finch CA. Erythropoietin regulation of erythropoiesis. In: Red Cell Manual, 7th ed. Philadelphia, PA: FA Davis Company; 1996:25.

36. Dusenbery KE, McGuire W, Holt PJ, et al. Erythropoietin increases hemoglobin during radiation therapy for cervical cancer. Int J Radiat Oncol Biol Phys 1994;29:1079-1084.

37. Henke M, Guttenberger R, Barke A, et al. Erythropoietin for patients undergoing radiology: A pilot study. Radiother Oncol 1999;50:185-190.

38. Lavey RS, Dempsey WH. Erythropoietin increases hemoglobin in cancer patients during radiation therapy. Int J Radiat Oncol Biol Phys 1993;27:1147-1152.

39. Sweeney PJ, Nicolae D, Ignacio L, et al. Effect of subcutaneous recombinant human erythropoietin in cancer patients receiving radiotherapy: Final report of a randomized, openlabelled, phase II trial. Br J Cancer 1998;77:1996-2002.

40. Shasha D, George MJ, Harrison LB. Once-weekly dosing of epoetin- $\alpha$ increases hemoglobin and improves quality of life in anemic cancer patients receiving radiation therapy either concomitantly or sequentially with chemotherapy. Cancer 2003:98:1072-1079

41. Heckman JJ. Sample selection bias as a specification error. Econometrica 1979;47:153-161.

42. Spilker B. Quality of Life and Pharmacoeconomics in Clinical Trials, $2^{\text {nd }}$ ed. Philadelphia, PA: Lippincott Williams \& Wilkins; 1996.

43. Patrick DL, Gagnon DD, Zagari MJ, et al. Assessing the clinical significance of health-related quality of life (HrQOL) improvements in anaemic cancer patients receiving epoetin alfa. Eur J Cancer 2003;39:335-345.

44. Shasha D, Harrison LB. Anemia treatment and the radiation oncologist: Optimizing patient outcomes. Oncology 2001;15:1486-1491.

45. Ludwig H, Birgegard G, Barrett-Lee P, et al. Prevalence and management of anemia in patients (pts) with hematologic malignancies (HMs) and solid tumors (STs): Results from the European Cancer Anaemia Survey (ECAS) (Abstr). Blood 2002;100(11 pt 1):234a-235a.

46. Leyland-Jones B, on behalf of the BEST Investigators Study Group. Breast cancer trial with erythropoietin terminated unexpectedly. Lancet Oncol 2003;4:459-460.

47. Henke M, Laszig R, Rübe C, et al. Erythropoietin to treat head and neck cancer patients with anaemia undergoing radiotherapy: Randomised, double-blind, placebo-controlled trial. Lancet 2003;362:1255-1260.

48. Sabbatini P, Cella D, Chanan-Khan A, et al. Cancer and treatment-related anemia. National Comprehensive Cancer Network Clinical Practice Guidelines in Oncology, v.1.2004. Available at www.nccn.org. Accessed August 5, 2004. 